\title{
Paediatric Syncope: An Unfortunate Variant
}

\author{
Tyler Hynes ${ }^{\mathrm{a}}$, Samuel Walter Wak ${ }^{\mathrm{b}}$, Rosa McNamara, ${ }^{\mathrm{a}, \mathrm{b}, \mathrm{c}, \mathrm{d}}$, \\ Fergal Cummins ${ }^{\mathrm{a}, \mathrm{b}, \mathrm{c}}$
}

\begin{abstract}
We present a case report of 7 years old boy who presented with cardiac arrest after collapsing during physical activity at school. He had had previous syncopal episodes but with normal physical examination and investigations. Subsequent autopsy showed a congenital cardiac anomaly where the coronary sinus only gave rise to only a single right coronary artery from which the left coronary artery branched.
\end{abstract}

Keywords: Paediatric syncope; Congenital cardiac anomaly; Case report

\section{Introduction}

Syncope in children is a common problem encountered in the emergency room; an estimated $15 \%$ of children will experience an episode of syncope before reaching puberty. These children can often prove very challenging for emergency physicians, as although the majority of these events are benign, there is always the possibility that these events are the sole sign of a significant vascular, cardiac or meta-

Manuscript accepted for publication May 16, 2013

${ }^{\mathrm{a}}$ Graduate Entry Medical School, University of Limerick, Limerick, Ireland

${ }^{\mathrm{b}}$ Emergency Department, University Hospital Limerick, Limerick, Ireland

${ }^{c}$ Retrieval, Emergency and Disaster Medicine Research and Development Unit (REDSPoT), University Hospital Limerick, Limerick, Ireland

${ }^{\mathrm{d}}$ Corresponding author: Rosa McNamara, Emergency Department, Retrieval, Emergency and Disaster Medicine Research and Development Unit (REDSPoT), Graduate Entry Medical School, University of Limerick, Limerick, Ireland.

Email: rosa.mcnamara@ul.ie

doi: http://dx.doi.org/10.4021/jmc1287w bolic pathology. This case presentation highlights the difficulties and the serious consequences that surround managing paediatric syncope in the ED.

\section{Case Report}

A 7-year old boy presented to the emergency department (ED) following cardiac arrest. He had collapsed at school and was seen to have seizure like activity. He rapidly developed cardiorespiratory arrest. Bystander cardiopulmonary resuscitation was commenced immediately by school staff. Resuscitative effort continued with the arrival of paramedics when he was noted to have pulseless electrical activity. When the patient arrived in the emergency department he continued to have pulseless electrical activity. Resuscitative efforts continued for 45 minutes unsuccessfully.

On review of the boys history he had previously attended the ED aged 4 after vomiting and collapsing at a friend's birthday party. The episode lasted approximately 180 seconds. No seizure like activity or post-ictal period was reported. Physical examination on that occasion including neurological and CVS were normal, as was the child's ECG. A diagnosis of vaso-vagal syncope secondary to vomiting was made.

The patient was subsequently followed up an outpatient by his paediatrician. He had complained of further episodes of breathlessness and tachycardia during exertion, associated with seizure like activity. The patient had been referred for further investigation to a paediatric cardiologist but was found to have no significant abnormalities noted on further ECGs and echocardiography with the exception of minor mitral regurgitation. He had also seen by a paediatric neurologist who could find no evidence of a seizure disorder.

\section{Post mortem examination}

The coroner performed an autopsy which demonstrated a number of anomalies; the patient's coronary sinus gave rise to only a single right coronary artery from which the left coronary artery branched. The proximal left coronary artery showed a stenotic thick walled vessel with a small narrow 
lumen, which did not continue distally. Microscopically the thickening of the vessel walled was due to fibrointimal hyperplasia. The left ventricular myocardium showed foci of ischemic fibrosis, likely representing past micro-infarcts. The coroner concluded that death was likely to due to arrhythmia triggered by an additional ischaemic event.

\section{Discussion}

Paediatric syncope is extremely common and most have benign aetiology [1]. Sinister aetiology is mostly cardiac in origin and these are in the form of structural or cardiac rhythm abnormalities.

Coronary artery of abnormal aortic origin occurs in $0.64 \%$ of births. Most of these children and adolescents are asymptomatic [2]. However, syncope and sudden death may be the presenting symptoms. The most common abnormality is the left circumflex originating from the right sinus of Valsalva. Physical examination and diagnostic studies are usually unrevealing in the absence of myocardial infarction or symptoms of ongoing ischaemia [3]. If coronary artery anomaly is suspected, echocardiography may establish the diagnosis [4]. CT angiography is the historical gold standard for diagnosing coronary artery abnormality [5]. Non-invasive coronary magnetic resonance angiography may also be used.

Our patient had a rare and serious cause of paediatric syncope which was not detected until after death. It illustrates the difficulties that exist when trying to determine whether a serious aetiology underlies the presentation of paediatric syncope not just to the ED, but to paediatric specialist services.

\section{Bottom line}

A high index of suspicion for a cardiac cause must be present when evaluating any patient presenting with the following symptoms; syncope due to fright or emotional stress, exercise induced syncope, syncope while in the supine position or a family history of sudden cardiac death or arrhythmia.

With repeated presentation, deliberate investigation to rule out rare causes of syncope should be undertaken.

\section{References}

1. Massin MM, Bourguignont A, Coremans C, Comte L, Lepage P, Gerard P. Syncope in pediatric patients presenting to an emergency department. J Pediatr. 2004;145(2):223-228.

2. Kimbiris D, Iskandrian AS, Segal BL, Bemis CE. Anomalous aortic origin of coronary arteries. Circulation. 1978;58(4):606-615.

3. Cheitlin MD, De Castro CM, McAllister HA. Sudden death as a complication of anomalous left coronary origin from the anterior sinus of Valsalva, A not-so-minor congenital anomaly. Circulation. 1974;50(4):780-787.

4. Frommelt PC, Frommelt MA, Tweddell JS, Jaquiss RD. Prospective echocardiographic diagnosis and surgical repair of anomalous origin of a coronary artery from the opposite sinus with an interarterial course. J Am Coll Cardiol. 2003;42(1):148-154.

5. Graham TP, Jr., Driscoll DJ, Gersony WM, Newburger JW, Rocchini A, Towbin JA. Task Force 2: congenital heart disease. J Am Coll Cardiol. 2005;45(8):13261333. 